Review

\title{
Design and licensing strategies for the fluoride-salt-cooled, high-temperature reactor (FHR) technology
}

Raluca O. Scarlat ${ }^{\text {a, }}$, Michael R. Laufer ${ }^{\text {b }}$, Edward D. Blandford ${ }^{\mathrm{c}}$, Nicolas Zweibaum ${ }^{\mathrm{b}}$, David L.

Krumwiede $^{\mathrm{b}}$, Anselmo T. Cisneros ${ }^{\mathrm{b}}$, Charalampos Andreades ${ }^{\mathrm{b}}$, Charles W. Forsberg ${ }^{\mathrm{d}}$, Ehud Greenspan ${ }^{\mathrm{b}}$, Lin-Wen $\mathrm{Hu}^{\mathrm{e}}$ and Per F. Peterson ${ }^{\mathrm{b}}$

${ }^{a}$ Department of Engineering Physics, University of Wisconsin, Madison, 1500 Engineering Dr, Madison, WI 53711, USA

${ }^{b}$ Department of Nuclear Engineering, University of California, Berkeley, 4118 Etcheverry Hall, MC 1730, Berkeley, CA 94720-1730, USA

${ }^{c}$ Department of Chemical \& Nuclear Engineering, University of New Mexico, 259 Farris Engineering Center, Albuquerque, NM 87131, USA

${ }^{d}$ Department of Nuclear Science and Engineering, Massachusetts Institute of Technology, 77

Massachusetts Avenue, 24-107, Cambridge, MA 02139, USA

${ }^{e}$ Nuclear Reactor Laboratory, Massachusetts Institute of Technology, 138 Albany Street, NW12-220, Cambridge, MA 02139, USA

*Corresponding author.Tel: +1 5105173685.E-mail address:rscarlat@nuc.berkeley.edu.

\begin{abstract}
Fluoride-salt-cooled, high-temperature reactor (FHR) technology combines the robust coated-particle fuel of high-temperature, gas-cooled reactors with the single phase, high volumetric heat capacity coolant of molten salt reactors and the low-pressure pool-type reactor configuration of sodium fast reactors. FHRs have the capacity to deliver heat at high average temperature, and thus to achieve higher thermal efficiency than light water reactors. Licensing of the passive safety systems used in FHRs can use the same framework applied successfully to passive advanced light water reactors, and earlier work by the NGNP and PBMR projects provide an appropriate framework to guide the design of safety-relevant FHR systems. This paper provides a historical review of the development of FHR technology, describes ongoing development efforts, and presents design and licensing strategies for FHRs. A companion review article describes the phenomenology, methods and experimental program in support of FHR.
\end{abstract}

\section{Keywords:}

- Liquid fluoride salt

- Reactor design

- Molten salt

- Licensing framework and reactor design

- Passive safety systems

(C) 2014. This manuscript version is made available under the Elsevier user license http://www.elsevier.com/open-access/userlicense/1.0/ 


\section{Introduction}

Fluoride-salt-cooled, high-temperature reactor (FHR) technology uses a novel combination of fluoride salt coolant and high-temperature coated-particle fuel. The low-pressure primary system delivers heat in the temperature range from $600^{\circ} \mathrm{C}$ to $700^{\circ} \mathrm{C}$ or higher, uses thin-walled reactor vessels as do sodium-cooled fast reactors (SFRs), and enables power densities between 10 and $30 \mathrm{MW} / \mathrm{m}^{3}$, compared to typical power densities below $5 \mathrm{MW} / \mathrm{m}^{3}$ for modular helium reactors [1, pp. 4-6], [2]. FHRs use natural circulation for emergency decay heat removal, and incorporate a number of other passive and inherently safe features.

Recent studies of FHRs [3]-[6] suggest the potential to achieve attractive economic performance while meeting high standards for reactor safety and security. Based on this earlier work, the U.S. Department of Energy (DOE) initiated an Integrated Research Project (IRP) in January 2012 with the Massachusetts Institute of Technology, the University of California, Berkeley, and the University of Wisconsin-Madison, to develop the technical basis to design, develop, and license commercially attractive FHRs.

To initiate this project, the IRP hosted a series of four expert workshops during 2012 to review technical and licensing issues for FHRs. The comments of the experts attending the workshop were integrated into four white papers covering the topics of each of the workshops. These four FHR white papers set the groundwork to identify key technologies and challenges in the development of FHRs [7][10].

This article provides an overview of the FHR white papers, and focuses primarily on the material developed in the first white paper, FHR Subsystems Definition, Functional Requirement Definition, and Licensing Basis Event (LBE) Identification [7]. The first section of this article reviews the history of the development of FHR technology, summarizes current activities, and describes each of the FHR white papers. The rest of the article discusses the overall strategy for design and licensing of FHRs; how to identify high-level functional requirements of major FHR systems, structures, and components (SSCs); and how to identify a range of LBEs that should be considered in design and in the development of modeling tools and supporting experiments, including a discussion of lessons from the Fukushima Daiichi accident for severe external beyond design basis events (BDBEs). A companion review article focuses on the material developed in the second and third FHR white papers [11].

\subsection{Historical Perspective}

The history of molten salts as working fluids for nuclear reactors goes back more than 50 years and begins with Ed Bettis and Ray Briant of Oak Ridge National Laboratory (ORNL) shortly after World War II. They were in charge of designing a nuclear-powered aircraft. They selected molten fluoride salts primarily as a result of the salts' high-temperature performance and overall chemical stability. In 1954, the first small molten-salt reactor, the Aircraft Reactor Experiment, was built and achieved a power of 2.5 MWth. The primary fuel circuit was cooled by sodium, and the circulating fuel comprised a $\mathrm{NaF}-\mathrm{ZrF}_{4}-\mathrm{UF}_{4}$ mixture. The maximum operating temperature of the fuel was $882^{\circ} \mathrm{C}$ [12], [13].

The military need for nuclear-powered aircraft decreased sharply in the latter half of the 1950s as attention shifted toward ballistic missile technology. Following the closing of the Aircraft Reactor Experiment in 1956, Alvin Weinberg pushed to create the Molten Salt Reactor (MSR) to see whether this technology could be adapted for civilian power reactors. Shortly after, the Molten Salt Reactor Experiment (MSRE) was approved, and design started in the summer of 1960 at ORNL. It was intended to simulate only the fuel stream of a two-fluid breeder reactor. Ultimately, an 8-MWth MSRE was built for just over $\$ 8$ million (1961 dollars) [13]; it took approximately 3 years to construct. The initial fuel for the MSRE was ${ }^{7} \mathrm{LiF}-\mathrm{BeF}_{2}-\mathrm{ZrF}_{4}-\mathrm{UF}_{4}$ [14], while the intermediate coolant was clean (i.e. fuel-free) ${ }^{7} \mathrm{LiF}-2 \mathrm{BeF}_{2}$ (flibe). In 1968 , the original fuel was replaced with ${ }^{233} \mathrm{U}$, making it the first reactor to run on this fissile fuel. It had a graphite moderator and used Alloy $\mathrm{N}$ for its structural material. The MSRE ran from 1965 to 1969 at a typical operating temperature of $600^{\circ} \mathrm{C}$ [14]. During operation, the concentrations of $\mathrm{CrF}_{2}$ in the fuel salt were observed to rise by a level indicating an average corrosion rate of $0.1 \mathrm{~mm}$ (4 mils) per year, and after shutdown it was found that fission products had caused intergranular attack. In contrast, the intermediate 
loop with clean salt, as would be used in FHRs, experienced no detectable corrosion after over 26,000 hours of operation [15].

For a variety of reasons, the MSR program in the United States was ultimately shut down in the middle of the 1970s. At that time, the objectives of the MSR program were shifting toward a thorium breeder technology known as the Molten Salt Breeder Reactor, which competed with the uranium-plutonium Liquid Metal Fast Breeder Reactor program being developed at Argonne National Laboratory [13]. The fluoride salts were subsequently studied for use as coolants for fusion reactors, but it was not until the early 2000s that research in molten salts as fission reactor coolants was renewed in the United States. The FHR reactor concept with fuel being solid and separate from the coolant represents a significant departure from the liquid fuel MSR technology developed in the 1960s.

Since the 1970s, high-temperature, gas-cooled reactor (HTGR) technology has been studied because of the potential advantages of delivering heat at substantially higher temperatures than are achievable with light water reactors (LWRs). The advantages of higher temperatures include increased efficiency for power conversion; reduced waste heat generation, which can reduce or eliminate the need for cooling water and thus increase siting flexibility; and the capability to provide co-generation and process heat services. It has proven challenging, however, to develop helium-cooled reactor designs with passive decay heat removal capability that have sufficiently low construction costs to compete economically with conventional LWRs. As part of the effort to commercialize HTGRs, a wide experience base with manufacturing and performance of coated-particle fuel has been established in the U.S., U.K., Germany, France, China, Russia, Japan, South Africa, and the Republic of Korea [16]. The FHR also uses coated-particle fuel, and relies on much of the experience base with HTGR fuel.

\subsection{FHR Development Activities}

Research on salt-cooled, high-temperature reactors was initiated in 2002 with studies of a Liquid Salt Very High Temperature Reactor (LS-VHTR) aimed at achieving high core outlet temperatures (950 to $1000^{\circ} \mathrm{C}$ ), derived from the work at ORNL in the 1960s and 1970s [17]. The LS-VHTR was essentially a modified helium-cooled VHTR, using liquid salt as the primary coolant, which operated at near atmospheric pressure and substantially greater power density - two to six times higher - than heliumcooled reactors [18]-[20]. As shown in Table 1, FHR core power densities are in the range of 10 to 30 $\mathrm{MW} / \mathrm{m}^{3}$; gas cooled reactor core power densities are $4.8 \mathrm{MW} / \mathrm{m}^{3}$ for the $400 \mathrm{MWth}$ pebble bed modular helium reactor (PBMR), and $6.6 \mathrm{MW} / \mathrm{m}^{3}$ for the $600 \mathrm{MWth}$ gas turbine modular helium reactor [1, pp. 46], [2]. While substantially higher than these HTGRs, FHR core power densities are lower than for PWRs $\left(105 \mathrm{MW} / \mathrm{m}^{3}\right)$ and SFRs $\left(321 \mathrm{MW} / \mathrm{m}^{3}\right)$. Based upon the metric of primary system volume, given by the specific reactor vessel power $\left(\mathrm{MWe} / \mathrm{m}^{3}\right)$, FHRs reactor vessels are much more compact than PBMRs and S-PRISM, and less compact than PWR reactor vessels.

As comparisons like these were made, researchers also quickly recognized that liquid salt coolants could achieve the same average primary coolant temperature with a significantly lower maximum outlet coolant temperature compared to helium-cooled reactors. Because thermal efficiency depends primarily on average coolant temperature, rather than peak temperature, the LS-VHTR concept evolved into the Advanced High-Temperature Reactor (AHTR), and then FHR with a core outlet temperature sufficiently low to allow the use of existing American Society of Mechanical Engineers code-certified structural materials for the primary pressure boundary [3]-[6], [21]-[23].

The most recent conceptual designs classified as FHR technologies include the Pebble Bed FHR (PBFHR) at UCB [24], [25], the Small Modular AHTR (SmAHTR) at ORNL [26], the large central-station AHTR at ORNL [27],[79], and the solid fuel thorium molten salt reactor (SF-TMSR) at the Shanghai Institute of Applied Physics (SINAP) in China.

SmAHTR is a 125-MWth cartridge-core, integral-primary-system FHR that uses fixed plate-type fuel. The ORNL 2012 AHTR is a large 3400-MWth fixed plate fuel variant of the FHR. This 2012 AHTR design implements novel designs for fuel and refueling, and demonstrates a practical application of supercritical steam for power conversion based upon extensive experience in fossil power plants. 
The PB-FHR under development at UCB uses a randomly packed pebble core configuration with capability for online refueling [24], [25]. The modular 900-MWth pebble bed AHTR (PB-AHTR) was the original reference design and is a hybrid pool/loop-type reactor system [5], [28]. Subsequently UCB has developed a small, modular 236-MWth Mark-1 (Mk1) PB-FHR design that is smaller than the earlier PBAHTR designs. The Mk1 design eliminates the guard vessel and buffer salt, and the intermediate salt loop. Salt-to-air heat exchangers transport heat to an open air Brayton cycle [25], [29].

The SF-TMSR is the solid fuel variant of the molten salt reactor program at SINAP. A 2-MWth test reactor, with capability for expansion to $10 \mathrm{MWth}$, is currently under development and will be built in $\mathrm{Da}$ Feng city, $250 \mathrm{~km}$ from Shanghai. The test reactor has fixed ordered lattice pebble fuel.

Table 1 summarizes other key design parameters for the Mk1 PB-FHR, the ORNL 2012 AHTR, and other reactors including a conventional Generation II Westinghouse 4-loop pressurized water reactor [80], a helium cooled Pebble Bed Modular Reactor [81], and the S-PRISM sodium fast reactor [82].

\subsection{White papers}

FHRs exhibit different thermal hydraulic, neutronic and structural mechanics phenomena compared to conventional reactors, and to more extensively studied advanced nuclear reactor concepts. They use a novel combination of fuel, coolant and materials: graphite-matrix, coated-particle fuel; fluoride salt coolant; graphite moderator materials; and high-temperature metallic structural materials. The four white papers issued after the four FHR expert workshops held in 2012 outline the novel aspects of FHR technology and propose a technology development path. The initial drafts of the white papers were prepared before the respective workshops by graduate students and postdoctoral scholars, and the comments of the experts attending the workshops were subsequently integrated. The experts who attended the workshops represent industry, academia, and national laboratories.

Recently, closely related progress has been made in high-temperature design and materials as a part of U.S. research for the Next Generation Nuclear Plant (NGNP) and for liquid metal reactors (LMRs). A similar set of white papers was generated by the NGNP program and covered regulatory technology development, fuel qualification, analytical validation and verification, defense in depth, classification of SSCs, LBE selection, core design and heat removal, mechanistic source terms, air and water ingress, nuclear-conventional island boundary, co-location at industry site, and emergency preparedness [16], [30]. Much of the NGNP material is also applicable to FHRs, and the FHR white papers focus on issues that are specific to FHRs.

The first FHR white paper [7] presents an overall framework to guide the design and licensing of future FHRs. It proposes a system decomposition scheme, presents key FHR constituents and materials selection options, and identifies functional requirements for the key subsystems of FHRs. A set of six safety design criteria (SDC) are proposed as the top level safety requirements for FHRs, and defense-indepth strategies for meeting each of the requirements are suggested. Likewise, the white paper proposes an initial set of LBEs and system operating states to be used in developing safety system designs and models for FHRs. Workshop participants also emphasized the importance of developing economic and cost models to guide design decisions and optimization. The experts had extensive experience in the areas of advanced reactor design, LWR design, licensing, instrumentation and control and modular construction, HTGRs, SFRs, MSR, technology-neutral licensing, and the Code Scaling, Applicability, and Uncertainty methodology.

The second white paper [8] reviews the characteristic phenomena in FHRs and existing modeling and experimental basis for FHR technology. It identifies figures of merit, available modeling tools and experimental facilities, and efforts required to validate simulation tools in the domains of thermal hydraulics, neutronics, structural mechanics and multiphysics. A credible quality assurance program must be implemented for a nuclear regulatory body to accept collected experimental data as a validation basis for licensing the FHR. The experts had extensive experience in the areas of thermal hydraulic modeling and separate and integral effects test experiments, neutronic modeling and experiments, and transient thermal stress and structural response for high-temperature structural materials. 
The third white paper [9] reviews state-of-the-art FHR materials and fuels, and the issues that arise from their application to FHRs. This white paper discusses the performance of FHR fuel, quality verification requirements and development needs. The baseline FHR design assumes limited use of carbon fiber reinforced composites and silicon carbide fiber reinforced composites for structures in high neutron rate regions of the core. Type 316 stainless steel and Alloy $\mathrm{N}$ are two candidate alloys to make the reactor vessel and intermediate heater exchangers. Only a single metallic structural material should be used in contact with the FHR coolant salts to prevent electro-chemical interactions, and time-dependent creep deformation of reactor structural materials must be limited. Optimal redox control is important to minimize corrosion of metallic materials and avoid graphite damage. Tritium production is a key issue associated with FHRs that needs to be managed, and this white paper discusses tritium production, transport and recovery. The beryllium contained in flibe - the baseline FHR primary salt - is toxic, and this white paper discusses beryllium safety measures. The experts had extensive experience in the areas of low-pressure equipment, coated-particle fuel, metallic, graphite and composite structural materials, corrosion and fluoride salt chemistry control, in-service inspection, on-line monitoring, and maintenance in hightemperature environments.

The fourth white paper [10] provides input to the institutional challenges that must be addressed in the FHR roadmap - including the commercialization strategy, the fuel cycle, combined cycle power conversion options and the capability to provide peaking power, and lithium-7 enrichment. It also discusses functional requirements and goals for an FHR test reactor as well as ownership options. The white paper recommends a scaling approach needed to address these functional requirements and goals, including how to maximize the information that an FHR test reactor can produce to predict the operational reliability of commercialscale plants and their response to LBEs. The experts had extensive experience in the areas of hightemperature component test facilities, test reactor design, licensing, deployment and operation, and national policy and utility goals and requirements for advanced reactor development.

The FHR workshop white papers provide a foundation for the future effort needed to develop a larger number of more comprehensive white papers on key areas for FHR licensing and commercialization, which would be needed for U.S. Nuclear Regulatory Commission (USNRC) pre-application review of a commercial prototype FHR design. The FHR workshop participants identified the set of key topics for future white papers that will be needed for the deployment of FHRs, including LBEs, SDC and functional requirements, general design criteria, beryllium and tritium control, economics, overcooling control, and coolant inventory control.

\section{Design}

In the ten years of research since the FHR concept was first proposed [3], multiple conceptual designs have been generated [24]-[29], [31], and a basic understanding of key reactor design approaches has emerged. UCB has proposed a workflow [25], [29] to aid in the continued design and development of FHR technologies; this workflow was originally developed to provide a framework for generation of computeraided design (CAD) models. Subsystems and components are populated using functional requirement tables and are then categorized as priority-explicit, explicit, or non-explicit. This distinction is made to focus the design and CAD modeling efforts on subsystems unique or novel to the FHR. Components and subsystems are grouped together to create systems. Additional attention and detail are given to design of important systems. Next, low-fidelity CAD models are created from all of the high-fidelity system CAD models. These are then combined into the overall plant layout. A flowchart generated to depict this workflow shows the hierarchical decomposition and design prioritization, as well as some functional requirement information. Items are grouped into different ventilation zones by a combined assessment of radiation hazard and physical protection needs, and below-grade and above-grade components and systems are identified. This workflow tool has proven helpful in coordinating a multi-person design and CAD modeling effort as well as in providing a visual mapping of the components, subsystems and systems.

This section discusses the approach to system decomposition and the definition and use of functional requirements. While the range of FHR design may vary broadly, the material selection is typically constant among all design variants. This section also presents the material options for FHR, including solid, liquid, and gas components. 


\subsection{FHR System Decomposition and Functional Requirements}

The system decomposition approach for the FHR, shown in Figure 1, integrates the higher-level plant, areas, systems, subsystems, and components (PASSC) convention used by the NGNP program [32] with the decomposition paradigm for a hierarchical two-tier scaling (H2TS) analysis methodology [33]-[35]. It is convenient to use this convention because the SSC terminology is important in safety classification established by the Code of Federal Regulations (CFR), 10 CFR 50.69 [36], and it easily maps onto the convention.

The H2TS system decomposition paradigm includes the system, subsystems, modules, constituents, geometrical configurations, physical phases (gas, liquid, and solid), fields, and phenomena. Fields were chosen to be consistent with scaling methods. Using this paradigm allows for direct application of phenomena identification and ranking table results to the design of scaled experiments. It also facilitates application of analytical calculations and scaling analysis to support qualitative phenomena ranking rationale.

In the FHR system decomposition, the module level of the H2TS paradigm coincides with the component level of the PASSC convention. Functional and safety requirements are defined at the SSC level; phenomena identification and ranking, which subsequently prioritizes modeling and experimental requirements, is performed at the lower levels of the system decomposition.

Functional requirements for FHR systems and subsystems guide the design and development of FHRs to ensure that regulatory and other requirements, as well as performance goals are met. Because detailed designs for FHR systems have not yet been developed, the functional requirements also establish a set of performance assumptions, on which system performance and optimization analyses can be based. The NGNP program took a similar approach to documentation of the requirements for an NGNP plant [37].

Functional requirements identification is an iterative process with identifying and ranking phenomenology, and with LBE definition [38, pp. xi-xv]. SSC safety classification will then follow. The FHR Subsystems Definition, Functional Requirements Definition, and LBE Identification White Paper documents a first set of FHR hierarchical functional requirements [7], which are based on the consensus of the FHR workshop participants and the FHR advisory board. The top level requirements guiding the definition of system and subsystem functional requirements include SDC, economics, investment protection, safeguards, and physical security.

Material selection is an important set of decisions guided by the list of functional requirements. It is advantageous to take these kinds of decisions as early as possible in the design process, in order to guide material development experimental and modeling efforts, which can entail lengthy campaigns. The subsequent section discusses options for FHR material selection.

\subsection{Material Selection}

FHRs use tristructural isotropic (TRISO)-coated-particle fuels originally developed for HTGRs [39][41]. Options for the fuel kernel include low enriched-uranium, transuranics, and thorium. The fuel kernel is encapsulated in graphite and silicon carbide layers that contain all fission products, forming highly robust sub-millimeter sized fuel particles. The fuel particles are mixed with a graphite matrix material, and compacted into fuel elements of the desired shape; the options for the fuel element geometry that are currently being pursued for FHRs are pebbles and plates.

Under DOE's NGNP program, the U.S. has reestablished the capability to fabricate, irradiate, and perform post-irradiation examination on coated-particle fuels. The new coating and compacting methods developed at ORNL have been proven to produce fuel with exceptionally high quality and performance. An NGNP fuel qualification white paper [16] provides a detailed review of the current regulatory basis for licensing coated-particle fuels including USNRC regulations, policy statements, guidance documents, and licensing precedents from earlier U.S. HTGRs; summarizes existing understanding, data and analysis methods regarding coated-particle fuel performance; reviews fuel designs and resulting fuel service conditions and performance requirements; and recommends an approach for qualification of NGNP fuel. 
These existing NGNP capabilities are important to the development of similar coated-particle fuels for FHRs.

There are a number of differences in the application of TRISO-coated-particle fuels to FHRs, as opposed to HTGRs. FHRs operate at power densities two to six times higher than those of HTGRs. Because the FHR coolant is an effective moderator, FHR fuels optimize to significantly higher heavy metal loading than HTGR fuel. In general, compared to HTGR fuels, FHR fuels will operate with substantially higher particle powers and particle packing densities within the graphite matrix. Thus, while FHRs can use the same coated-particle technology as HTGRs, research and development is needed to demonstrate methods to fabricate FHR-unique fuel element geometries. The fuel element designs of interest for FHR include pebble fuel and fixed-fuel variants.

A major benefit of the high particle powers used in FHRs, and of continuous fuel circulation, for pebble fuel, is that the fuel reaches full discharge burn up rapidly, typically in around one year for FHR pebble fuels. Therefore, the time to develop, test, and qualify new fuels for FHRs has the potential to be much shorter than for typical reactors, whose fuel reaches full discharge burn up in four to six years. Furthermore, the fuel element for pebble fuel is sufficiently small that full-element test capsules can be designed both for the Advanced Test Reactor at Idaho National Laboratory and High Flux Isotope Reactor at ORNL [42]. Unlike pebble fuel, the FHR fixed fuel, which is plates that are a few meters in length [43], [44], would likely require an initial set of coupon irradiation tests, followed by full-element irradiation tests, similar to the irradiation campaign for Reduced Enrichment for Research and Test Reactors [45]. FHR fuel qualification can take advantage of the work done for NGNP fuel qualification campaign, leveraging the NGNP plans for design of irradiation experiments, post-irradiation evaluation, fuel fabrication, and quality assurance [16], [41]. New fuel development normally takes over a decade, and the possibility of leading a fuel qualification campaign that can be completed in three to four years is a significant advantage for FHRs.

The selection criteria for FHR structural materials is a major focus of the FHR Materials, Fuels and Components White Paper [9]. Structural materials required for FHRs largely overlap with those that have been studied and developed for the NGNP. The state of the art in high-temperature reactor structural materials and the status of U.S. NGNP development efforts have been summarized in one of several Idaho National Laboratory white papers reviewing NGNP design and licensing issues [46]. This NGNP work, and the new capabilities that have been developed under the NGNP program, provide an important foundation for FHR development.

There are three categories of structural materials: metallic structures and components, ceramic structures and components, and building structures. Among the metallic components, the options for pressure vessel and piping include 316 stainless steel (SS 316), Alloy N, clad Alloy 800H, and clad Alloy 617; the options for heat exchangers and core internal structures include Alloy N, SS 316, clad Alloy 800H, and new advanced alloys. For chemistry and corrosion control simplicity, a single metallic alloy should be selected for all metallic materials contacting the coolant salt. Ceramic structures and components include the reflectors that will be made of graphite, and some core internal structures, which can be made of graphite, baked carbon, carbon-reinforced composite, or $\mathrm{SiC} / \mathrm{SiC}$ composites. The selection of internal structures materials depends on the level of development of the material for use in irradiation environments, and on the functional requirements of each specific component.

Building structures will be made of steel-plate/concrete composites, similar to the AP-1000 LWR, several of which are currently under construction [47], [48]. In the concrete for the reactor cavity structure, basaltic aggregate or other advanced additives (such as glass fiber reinforcing) that do not generate gas when overheated will be used. Limestone-based aggregate must be avoided because when overheated it can generate large volumes of carbon dioxide [49, pp. 4.4-1].

FHRs use low-volatility fluoride salts to transport heat. The primary candidate and baseline primary coolant for all current FHR designs is flibe. Alternative primary coolants may be explored, in order to avoid lithium and beryllium containing salts that under neutron irradiation produce tritium, which diffuses through metals at high temperature requiring tritium management systems to control tritium air emissions. Avoiding beryllium containing salts also eliminates the need for chemical management systems to prevent 
beryllium exposure of workers or the population; this is particularly of interest to reactors designed for transportability and deployment to remote locations. However, from the point of view of fuel utilization and negative temperature reactivity feedback, flibe is the best coolant among all other fluoride salt mixtures [50].

Secondary coolants may be used for the intermediate heat transport salt, for the secondary loop of the natural circulation decay heat removal system - the direct reactor auxiliary cooling system (DRACS) - and for the buffer salt that fills the space between the reactor vessel and the guard vessel and that is available for salt inventory addition in the event of vessel rupture. Candidates for intermediate heat transport salt include fluoride salts $\left(\mathrm{KF}_{\mathrm{Z}} \mathrm{ZrF}_{4}\right.$, flibe or flinak), fluoroborate salts (e.g. $\left.\mathrm{NaBF}_{4}\right)$, magnesium chloride salts, or liquid metals (e.g. NaK). Buffer salt alternatives include sodium fluoroborate and others. The PB-FHR design eliminates the intermediate salt loop and the buffer salt, for simplicity and improved power conversion efficiency. Candidates for the DRACS secondary loop fluid include fluoride salts (flibe, flinabe, flinak, or $\mathrm{KF}^{-} \mathrm{ZrF}_{4}$ ), magnesium chloride salts, or liquid metals (e.g. NaK). For simplicity, and because the DRACS secondary coolant liquid inventory is small, PB-FHR design uses the same fluid as the primary coolant; this design decision eliminates the probability of primary coolant contamination in the event of a DRACS heat exchanger tube leak.

Other key fluid selections for FHRs are the DRACS and shutdown cooling heat sink fluids and reactor cavity cooling fluid, which can be water or ambient air; the power conversion fluid, which can be ambient air, helium, carbon dioxide or steam; the cover gas for the primary coolant and for fuel transfer and storage, which in the baseline design is argon; the reactor cavity gas, which can be argon or dry air; and the filtered confinement gas, which will be filtered ambient air. If water is selected for any of these applications, the possibility of water leakage into the primary coolant circuit must be managed, due to salt chemistry and corrosion concerns. It is to be noted, however, that upon contact with air or water flibe does not react violently.

\section{Framework for Safety Analysis}

Licensing by the USNRC represents a critical gateway for U.S. development and subsequent deployment of commercial FHRs. Therefore, a major element of FHR research and development focuses on ensuring that information needed to successfully license FHRs is developed and available when needed to support commercial demonstration and subsequent commercial deployment.

A central issue for the development of FHR technology is the goal of licensing by the USNRC. To license new, advanced reactor designs, the USNRC requires that they be demonstrably safe, in comparison to existing U.S. nuclear reactors [51, p. 60615]:

"Regarding advanced reactors, the Commission expects, as a minimum, at least the same degree of protection of the environment and public health and safety and the common defense and security that is required for current generation light-water reactors [i.e., those licensed before 1997]. Furthermore, the Commission expects that advanced reactors will provide enhanced margins of safety and/or use simplified, inherent, passive, or other innovative means to accomplish their safety and security functions."

The USNRC has extensive experience reviewing LMR technology. Publications such as the USNRC preliminary safety evaluation report of the Super-Power Reactor Innovative Small Module (S-PRISM) design are highly useful in identifying important technical gaps in key FHR technologies that are shared with the LMR [52].

The Pebble Bed Modular Reactor (PBMR) and more recently designs from the NGNP have undergone extensive pre-application discussion and review with the USNRC where preliminary licensing and design feedback was provided to the HTGR designers [e.g., [53]-[55]]. Much of this work, such as critical white papers assembled by the DOE [16], [30], is publicly available and highly instructive for developing a framework to guide the design and safety analysis of FHR technology. 
The HTGR design and licensing strategy can be best thought of as addressing a set of four fundamental elements in the reactor design certification process, which are listed in Table 2. They are rooted in the "risk triplet" concept, which proposes that risk-informed decision should be based on a triplet of information: scenario sets, probability distribution of frequency, and consequence with quantified uncertainty [56]. LBEs are the scenario sets and their corresponding frequency and consequence curve families, and the top level regulatory criteria (TLRC) identify what is acceptable risk in the "risk triplet" space. Deterministic scenarios and design conditions, and defense-in-depth are a complementary way to manage the possibility that the LBE analysis is incomplete and that important system vulnerabilities would otherwise remain unaddressed. Classification of SSCs and the corresponding special treatment requirements document the system availability assumptions that are made in the LBE analysis [57]-[59]. SDC define groups of functional requirements that are important to safety, documenting the design philosophy that ensures that the TLRC are met.

The reliability of FHR SSCs, as well as their response during transients and accidents, will depend greatly on the specific materials selected. The FHR Materials, Fuels and Components White Paper [9] provides a detailed review of dominant FHR materials degradation mechanisms (such as corrosion, erosion, wear, fouling and plugging, cyclic stress, and neutron irradiation) and associated proactive management methods that need to be understood to predict the reliability of FHR SSCs. It also identifies functional requirements for online monitoring, in-service inspection, chemistry control and operational envelopes, maintenance, and replacement for subsystems and components.

\subsection{Safety Design Criteria}

A technology-neutral licensing or safety analysis framework is an "iterative process for the application of defense-in-depth principles that takes into consideration uncertainties" [57]. This technology-neutral licensing framework has been studied and developed most extensively for application to HTGRs [60], [61]. For a reactor technology like the FHR, with many novel elements that do not have a significant experience base, the technology-neutral framework provides an approach to incorporate safety analysis early in the design process. The generation of FHR SDC is one of the products of using this framework, and the process is illustrated in Figure 2. Ultimately, the licensing process will follow design-specific guidelines that are risk-informed and performance-based.

The SDC proposed for FHRs are adapted from the PBMR "Required Safety Functions," and the LMR "Top-Level Safety Functions", which are listed in Table 3. The six PBMR "Safety Functions" are organized in a hierarchical structure that includes the first four of their "Required Safety Functions" along with additional "supporting safety functions," which are not required, but provide defense in depth [36]. Similarly, the modular HTGR identified a set of "Principal Design Criteria."

The proposed high-level SDC for FHRs [62] are as follows:

$\begin{array}{llll}\circ & \text { SDC 1: } & \text { Maintain control of radionuclides } \\ \circ & \text { SDC 2: } & \text { Control heat generation (reactivity) } \\ \circ & \text { SDC 3: } & \text { Control heat removal and addition } \\ \circ & \text { SDC 4: } & \text { Control primary coolant inventory } \\ \circ & \text { SDC 5: } & \text { Maintain core and reactor vessel geometry } \\ \circ & \text { SDC 6: } & \text { Maintain reactor building structural integrity. }\end{array}$

These FHR SDC are derived from criteria originally proposed for the PBMR [36], with the key change that the PBMR SDC to "prevent chemical attack" is replaced by "control coolant inventory" to reflect the fact that in FHRs the fuel is protected from contact with air or steam as long as it is immersed in the chemically non-reactive liquid coolant, and the SDC "control heat removal" is expanded to include "and addition" because FHRs include electrical and other heating systems to prevent overcooling.

SDC define key groups of functional requirements important to safety. They represent high-level safety requirements specific to FHRs and provide the primary framework to organize FHR design and safety assessment. They are used to develop a high-level strategy for ensuring safety of FHRs. Each element of the SDC defines a class of lower-level safety functions [7], that are met by a hierarchical list of 
systems that provide defense in depth and multiple barriers to release of radionuclides from the source term to the environment, for public and worker protection. For example, "Tritium management" is a safety function that is subordinate to "Maintain control of radionuclides." More than one system is involved in meeting this safety function, "coolant chemistry control," "cover gas chemistry control," "low pressure containment," "filtered confinement." The proposed subordinate safety functions for each of the SDC, in conjunction with other top-level end-user and stakeholder criteria, lead to a preliminary subset of the system and subsystem functional requirements, that are documented in the Appendix of the FHR Subsystems Definition, Functional Requirements Definition, and Licensing Basis Events Identification White Paper [7].

\subsection{Licensing strategy}

Current licensing of LWRs involves, along with other requirements, the submittal by the applicant of a Safety Analysis Report that documents how the design complies with a set of LWR-specific General Design Criteria (GDC) defined in Appendix A of 10 CFR 50 [63]. The applicant can propose appropriate modifications or additions to the GDC, where the specific reactor design achieves the intent of the GDC by other means (such as the use of passive rather than active safety systems). Historically, licensing for both HTGRs and SFRs has undergone the process of identifying which GDC were being met and which were inapplicable [52].

The LMR community, in developing American Nuclear Society (ANS) safety standard 54.1 (withdrawn at the time of publication for this article) for LMR licensing, focused on a strategy that closely adopts the current LWR-based licensing process, except where differences are mandated by unique features of LMR design. To do this, the ANS standard provides a set of GDC for LMRs, which are derived from the LWR-based GDC in Appendix A of 10 CFR 50 [63]. These LMR GDC maintain a one-to-one correspondence to the Appendix A GDC. The HTGR community has been developing an ANS safety standard 53.1 [64] for HTGR licensing, that adopts a technology-neutral framework that focuses on fundamental functions for reactor safety.

Upcoming work by a new committee of the ANS to create a safety standard for FHRs, ANS 20.1, will provide the basis to develop consensus-based FHR-specific GDC derived from existing LWR-specific GDC, to be used in licensing reviews. ANS 20.1 could be used by the regulator to judge if the FHR design conforms to the current regulatory requirements contained in 10 CFR 50 or 10 CFR 52 . The determination is made by reviewing the application against the USNRC standard review plan (may be tailored to account for unique design features) using the GDC as acceptance criteria. If the USNRC endorses ANS 20.1, then the ANS 20.1 requirements will be used in lieu of Appendix A of 10 CFR 50 as acceptance criteria. This was also the approach by which the Modular High-Temperature Reactor, Sodium Advanced Fast Reactor and PRISM were reviewed.

Figure 3 illustrates how the FHR GDC can be derived from the existing LWR GDC. One of the major goals of the new ANS safety standard for FHRs is to generate a consensus set of FHR-specific GDC, using a similar process to that applied in ANS 54.1 to develop LMR-specific GDC. In fact, many of the LMRspecific GDC apply directly to FHRs, because both are high-temperature, low-pressure reactor designs.

The initial step to reviewing each of the 64 LWR GDC and their applicability to FHRs is to define the overall safety philosophy for FHRs, which is done through the SDC and the strategy for meeting them. This framework can guide the review of the GDC for applicability to FHRs and provide a framework for ensuring completeness of the FHR-modified GDC. The purpose of the SDC is not to provide an alternative licensing path to 10 CFR 50 Appendix A (i.e. LWR GDC). Rather, its purpose is to ensure that the LWR GDC are appropriately adapted for the licensing of FHRs and to provide a framework for integration of safety analysis from the early stages of reactor design.

\section{Selection of LBEs}

The design process for FHRs seeks to develop a systematic methodology to incorporate regulatory, stakeholder, and end-user requirements. This process includes the combination of a risk-informed approach 
to the selection of anticipated operation occurrences (AOOs) and LBEs with the selection of conservative bounding events to cover BDBEs. This hybrid approach is intended to address the uncertainties for a new reactor class with a limited experience base, such as FHRs, and to provide the framework to shift towards a risk-informed selection of BDBEs after initial deployment.

The FHR approach to the selection of LBEs follows that proposed in the NGNP program where LBEs are the scenarios that are considered by the licensing process, and are used to derive design-specific performance requirements from SSCs [54]. Similar to the NGNP process, this method includes a combination of deterministic and probabilistic methods, but incorporates some additional flexibility that is appropriate for the current status of the FHR design.

The FHR is currently in a pre-conceptual design phase for which there are numerous systems that can be incorporated to meet general safety and licensing requirements, as discussed previously in this paper. These systems can be used to form the basis for the identification of events and evaluation of event sequences that are generally applicable to FHRs. However, the approach is not prescriptive in which licensing basis events will be most limiting to a specific FHR design, or which SSCs should be classified as safety-related to meet the TLRC. These important decisions will be based on specific FHR designs as they become more mature over time.

\subsection{Risk-Informed Approach for AOOs and design basis events (DBEs)}

The method to select AOOs and DBEs for FHRs closely resembles the risk-informed process proposed for the HTGR in the USNRC pre-application review of both the PBMR and NGNP [54], [55]. This process incorporates a probabilistic risk analysis (PRA) methodology to evaluate the safety characteristics of preliminary designs and to determine the appropriate TLRC that need to be satisfied for each class of events. The use of PRA also allows for a systematic evaluation of plant event sequences, which helps to ensure that a complete set of events is considered in the accident analysis.

To create a set of risk-informed event categories, the LBE selection process must develop a set of plausible initiating events based on a combination of informed judgment and a hierarchical system decomposition to develop failure modes for major reactor systems. The use of a hierarchical system decomposition is useful at the current design phase to ensure the most complete possible set of events given the limited number of specific design decisions. The focus of this process for the FHR should therefore currently be based on the failure modes of reactor systems as initiating event classes and should not seek to identify specific mechanisms that lead to the failure, which can be complex (and require analysis using fault trees). For example, the loss of the power conversion unit (PCU) can be treated as a single initiating event, even though it can be caused through a large variety of system or component failures that would involve a very complex fault tree. The use of engineering analysis and judgment should also be incorporated into the selection process to exclude events that are not plausible so that event sequences can be developed for the most significant initiating events.

In order to take advantage of the large experience base with LWRs, a set of initiating events developed from the system decomposition for the FHR can be grouped into the seven categories of initiating events used by the USNRC in the Standard Review Plan [66], as exemplified in Table 4. While initiating events are different based on the reactor technology, these event categories are technology-neutral and can be applied to the FHR. This approach is therefore able to integrate elements of the existing LWR review framework. This set of event categories is useful to evaluate the relative importance of FHR event sequences for different FHR design options and also in comparison to other reactor types. In the LBE selection process, each category will include similar event sequences in terms of system response to the required safety functions but will diverge in the specific systems that will be available depending on the initiating event.

This paper is intended to be applicable to a broad range of FHR designs. Some of the initiating events listed in Table 4 are eliminated for some of the FHR variants, through design choices, while for other variants they remain valid. For example, "loss of intermediate loop pumps" is not applicable to designs that have eliminated intermediate loops. Therefore Table 4 provides a reference point for the justification of design choices that lead to inherent safety (i.e. elimination of risks). 
The use of engineering judgment and systematic decomposition enables the introduction of riskinformed methods at an early stage in the iterative design process. The use of PRA in the selection of LBEs is based on the methods developed for the pre-application review for PBMR and NGNP [54], [55]. PRA provides benefits in the design process that improves the probability of establishing a comprehensive safety basis, will seek to optimize the safety characteristics, and provides a rational approach to identifying, understanding, and addressing uncertainties. These benefits apply for the use of PRA in the FHR design process through the quantification of both frequencies and consequences of potential accident sequences. The future development of a PRA for FHRs will mature in conjunction with specific design selections.

The conceptual design phase PRA suggested for FHRs would categorize events based on the anticipated frequency using assigned, rather than observed, system reliability requirements. The assigned frequencies translate to functional requirements for the subsystem performance; functional requirements are instrumental in guiding future design development, and documenting the assumptions on which the current analysis is based. The categorization for AOOs, DBEs, and BDBEs for FHR makes use of the approach developed for NGNP that assigns frequency ranges for each type of event:

- AOOs are defined as events that are anticipated to occur within the lifetime of a single plant and span a frequency range of several per reactor-year to a conservative lower bound of one per 100 reactor-years.

- DBEs include events that are anticipated to occur within the lifetime of a reactor fleet and span a frequency range from the AOO lower frequency limit to a conservative lower bound of one per 10,000 reactor-years.

- BDBEs are events that are not expected to occur in the lifetime of a reactor fleet but merit analysis to ensure that there is acceptable risk to the general population. Such events have a frequency range that extends to one per 1,000,000 reactor-years, but the NGNP uses a lower bound of one per 2,000,000 reactor-years to ensure that sequences just below the threshold are included. Events with lower frequencies are not viewed as contributing significantly to the overall system risk and do not require analysis.

These event frequencies are used to categorize and group accident sequences derived from PRA event trees. As with the risk-informed approach for PBMR and NGNP [30], [67], deterministic design basis accidents (DBAs) are selected from the limiting sequences for a family of related accidents that fall within the DBE frequency range. These DBAs are analogous to the accident sequences that are evaluated for LWRs under the Standard Review Plan [66], which deterministically can only take credit for safety-related SSCs. FHRs are expected to perform a similar deterministic analysis, but also to evaluate the positive and negative impacts that non-safety-related SSCs might cause.

The approach presented here for the FHR conceptual design phase should not include analysis of exposure dose because this stage of analysis introduces a significant amount of uncertainty, and the large margin-to-fuel thermal failure makes it difficult to define credible release pathways of radioactive material from the FHR fuel. The most likely pathways are expected to instead involve circulating activity, for example a failure of the tritium management and storage system or the release of fission product gases from defective particles or tramp uranium in the fuel [68]. These pathways are design-specific and will require study later in the FHR development process. The current effort seeks only to classify postulated accident sequences in general terms.

The approach classifies event sequences based on the anticipated frequency determined through the use of event trees. Figure 4 shows a sample event tree for an FHR in response to the loss of the PCU heat sink. The probabilities listed are notional and would need to be estimated based on fault tree analysis and a set of assumptions on component reliability. Heat removal decreases in the secondary system, which causes an increase in primary coolant temperature. The detection of off-normal conditions initiates reactor scram by the reactivity control system or reserve shutdown system. Decay heat is removed by the normal shutdown cooling system or failure of the normal shutdown system would result in decay heat removal by natural circulation in the DRACS loops. 
The right-hand columns of the event tree in Figure 4 show that this initiating event has one AOO sequence, one DBE sequence, one BDBE sequence, and two sequences that fall below the minimum frequency threshold. In this case, the AOO includes the initiating event and the proper functioning of all reactor systems, and the DBE is the protected loss of heat sink where the safety-related DRACS system functions. For the notional event probabilities listed in Figure 4, neither case is expected to result in the release of any radioactive material and both should be able to demonstrate compliance with the TLRC.

This simple example also illustrates the value of the PRA methodology in the early design process because it demonstrates the value of systems to reduce the probability of certain event sequences below the minimum event threshold. In this case, the presence of a normal shutdown cooling system is important from a risk perspective because it reduces the credibility of accident scenarios with failures of the DRACS heat removal capability. Sequences that include DRACS failure may be able to meet the TLRC, but would require more complex analysis and potentially additional design features to ensure the adequate removal of heat by some other pathway, such as through the cavity cooling system.

\subsection{Bounding Events Approach for BDBEs}

The approach for the selection of BDBEs presented here diverges from the risk-informed methodology for AOOs and DBEs and is based on a more conservative deterministic approach rooted in the USNRC licensing process for LWRs and the USNRC review of pre-application material submitted in support of the licensing of the General Electric (GE) S-PRISM in the mid-1990s. This approach includes the selection of a series of bounding event categories that place significant demands on the safety systems of the reactor design and envelope a wide range of BDBEs. This approach is recommended here for the early development stage of FHRs because it is directly applicable to new reactor designs with limited operational experience and robust inherent safety characteristics. The approach diverges from historical bounding event analysis in the use of portable equipment under severe accident mitigation guidelines (SAMGs) and emergency damage mitigation guidelines (EDMGs) to mitigate consequences for events where the plant damage state is uncertain. Future FHR licensing efforts should integrate risk-informed methods for BDBE classification when validation and reliability data might be available.

In its review of the S-PRISM pre-application material, the USNRC staff hesitated to accept the riskinformed approach for BDBEs submitted by GE [52]. In NUREG 1368, the staff indicated that "PRA can provide useful insights into event selection but that engineering judgment must ultimately be relied upon in the event selection to account for uncertainties." While recognizing value in the PRA process, the S-PRISM review shows that the USNRC staff was not confident enough in that process to use it as the basis for defining the most limiting accident sequences - i.e. BDBEs. Recent USNRC staff review of the NGNP licensing strategy indicates that conservative deterministic judgment remains a preferred approach for new reactor designs with limited performance and reliability data [69], even though this approach is not fully consistent with the shift towards risk-informed performance-based regulation [70]. An illustrative example may be the boron injection tanks that were installed in Generation II PWRs for reserve shutdown, that were subsequently determined to be unnecessary once extensive reliability data became available for the primary reactivity control systems and thus were abandoned in place. Resolution of these generic, high-level questions will likely require decision-making from the USNRC commissioners and introduces uncertainty in the environment for developing new reactor technologies. Therefore, a bounding event approach is recommended here for initial FHR development based on the large temperature margins to fuel failure and the inherent safety features of the reactor class.

A set of bounding event categories that should be evaluated for specific FHR designs is proposed here:

1. Unprotected overpower events

2. Station blackout

3. Protected loss of heat sink (LOHS) with additional failure of safety-related heat removal system

4. Unprotected LOHS

5. Protected loss of forced circulation (LOFC) with additional failure of safety-related heat removal system

6. Unprotected LOFC 
7. Large loss of primary coolant (e.g. vessel rupture)

8. Severe overcooling transient

9. Flow blockage (fixed fuel design only)

10. Failure of hold-down structures

11. Severe external events

Several bounding event categories, such as protected LOHS and LOFC, overlap with sequences that will fall in the DBE frequency range but the BDBE sequences will impose additional challenges to the safety-related SSCs. More detailed descriptions of possible BDBEs in each category are given in the FHR Subsystems Definition, Functional Requirements Definition, and Licensing Basis Events Identification White Paper [7]. Note that this approach seeks to integrate conservative engineering judgment for novel reactor concepts, but does not seek to constrain future FHR design options by designating which systems are required or should be classified as safety related. Therefore, the development of a set of bounding events for a specific FHR design would require an evaluation to determine if the proposed list is still applicable or if additional bounding events merit consideration.

There are several important distinctions between the analyses of bounding events for the FHR based on current analysis, performance-based regulation goals and the historic conservative licensing of LWRs such as LOCA analysis under 10 CFR 50 Appendix K [71]. First, the analysis of FHR BDBEs should be based on best estimate plus uncertainty methods for the analysis of reactor transients [72], [73]. Modern analysis and simulation methods will be used to design and license FHRs [74]; these methods can account for more realistic system response to initiating events. In these scenarios, the inherent characteristics of the fuel and materials for FHRs should reduce the consequences of the most severe accident sequences relative to the existing fleet of LWRs. Second, BDBE response should account for the reduced consequences associated with the implementation of SAMGs and EDMGs along with the use of portable equipment that may be stored on- or off-site. These strategies integrate recommendations from the USNRC Task Force following the accident at Fukushima Daiichi, which recognize the importance of effective consequence mitigation strategies [75]. For conservative bounding events, the primary performance objective is to maintain public health and safety, and the plant would likely not be in acceptable condition for a future restart. A complete PRA analysis for FHRs would likely generate a more realistic, risk-informed set of BDBEs that can be used in the design process to develop effective investment protection strategies where plant restart may be possible after BDBEs.

\subsection{Lessons from Fukushima for Severe External BDBEs}

The conservative bounding event approach to BDBEs described above is based on an approach that was viewed favorably by the USNRC in the mid-1990s for new reactor technologies and may still be a preferred approach for the USNRC staff. Much of the logic for this approach is still relevant for non-LWRs for internal events, but experience at the Fukushima Daiichi nuclear plant suggests that a different approach may be required for the analysis of externally initiated BDBEs. The inherent robustness of the FHR suggests that improved defense-in-depth and reduced consequences may be possible even in the most severe external events with significant system damage and common mode failures.

One important lesson from the events at Fukushima is that severe external events can introduce large uncertainties in the resulting state of the plant, which can be further exacerbated by the unavailability of adequate instrumentation under station blackout conditions. The response of operators in such conditions is not captured in the conservative bounding event approach because of defined assumptions about the duration of the events and which systems are available. Actual response in such conditions would be determined by operator decisions based on the available knowledge of plant conditions and the availability of plant systems or equipment transported to the site. These actions will be guided by the SAMGs and EDMGs, which need to be integrated into the licensing review for external BDBEs. Maintaining adequate capability to measure key plant state parameters should also receive special consideration so that operators can make informed decisions and execute proper actions based on the EDMG and SAMG.

Another important lesson from the accident at Fukushima is the importance of the capability to provide standard external connections for portable power or cooling fluid supplies, if plant systems are left in a 
non-functional state. The acquisition of new portable equipment to be stored at plant sites, and the capability to transport portable equipment to the reactor site by air has been implemented at many reactor sites in the U.S. as a response measure against external threats but could be of equal importance in severe external events where physical access on the ground may be limited. The USNRC recently completed an effort to quantify the benefits of these portable systems along with mitigation strategies, such as SAMGs and EDMGs, in severe accident analysis and found that they reduce the cases of core damage to only a small subset of the most severe LWR events [76]. The detailed design of FHRs may incorporate the capability to use water injection to remove heat if the DRACS chimneys become obstructed. Design of such systems would need to ensure that they do not create a significant release pathway risk and should be integrated into the PRA.

For severe external BDBEs, it is important to consider some of the unique inherent safety capabilities of FHRs relative to other reactor technologies. FHRs provide a very large thermal margin to fuel failure and a low-pressure inert coolant. Fluoride salts also have high solubility for most fission products, including cesium-137, which is the primary isotope associated with long-term land contamination from the Chernobyl and Fukushima accidents. The use of fluoride salts could enable a different approach to severe accident analysis in which the primary objective is to minimize the health consequences from the release of radioactive material and the secondary objective is to minimize the disruptions caused by land contamination. Under this alternative approach, design decisions can be made to minimize, and potentially eliminate, the aerial pathways of radioactive material that would lead to short-term consequences beyond the reactor site [77], [78]. This approach leads to three primary safety objectives:

- Minimize peak temperature. Under severe accident conditions, plant geometry cannot be guaranteed and heat must be removed through a combination of conduction and natural circulation, which will increase the temperature of the primary reactor system and reactor building. Heat removal pathways via building structures to the ground and atmosphere may be designed to maintain fuel temperatures below $1800^{\circ} \mathrm{C}$ (fuel thermal limit) and prevent the release of radioactive material from the fuel. Spent fuel in storage must also be considered.

- Minimize gas generation. Gas generation, especially non-condensable gases caused by high temperatures, acts as primary means to disperse radioactive material into the atmosphere before dispersion into the surrounding area. Gas generation, particularly carbon dioxide from concrete, can be reduced by material selection and may be sufficient to eliminate aerial pathways for radioactive material.

- Maintain coolant inventory. In the event of a release of radioactive material from fuel, a sufficient coolant inventory to cover the fuel also provides an effective sink for many fission products, particularly cesium-137. This design is inherently different from that of LWRs where with oxidizing conditions Cs-137 is volatile and can be readily released from damaged fuel. These differences offer a possibility for no long-term consequences from offsite releases.

Work to study severe accident conditions for FHRs has been limited, and design choices to eliminate BDBE consequences may be determined to be unnecessary or impractical. However, the possible elimination of offsite consequences appears to be unique to the combination of fuel and coolant in FHRs and merits consideration.

\section{Conclusions}

In the ten years of research since the FHR concept was first proposed, multiple conceptual designs have been generated. The most recent conceptual designs include PB-FHR at UCB, SmAHTR and AHTR at ORNL, and TMSR-SF at SINAP. FHRs exhibit different thermal hydraulic, neutronic and structural mechanics phenomena compared to conventional - and more extensively studied - advanced nuclear reactor concepts. There are, at the same time, multiple areas where the NGNP and LMR programs have developed key capabilities relevant to FHRs. In particular, the U.S. programs to develop coated-particle fuels for the NGNP, to develop graphite and ceramic composite materials and American Society of Mechanical Engineers code design rules for their use in the NGNP, and to develop high-temperature metallic materials for use in the NGNP and LMRs are of critical importance to the development of FHRs. 
Four FHR expert workshops were held in 2012 to outline the novel aspects of FHR technology and propose a technology development path. The set of four white papers that were generated as a product of the expert workshops were summarized here.

For FHR design and safety analysis, six high-level SDC based on earlier work by the NGNP and PBMR projects provide an appropriate framework to guide the design of safety-relevant FHR systems, structures, and components: SDC 1 - Maintain control of radionuclides, SDC 2 - Control heat generation (reactivity), SDC 3 - Control heat removal and addition, SDC 4 - Control primary coolant inventory, SDC 5 - Maintain core and reactor vessel geometry, and SDC 6 - Maintain reactor building structural integrity.

The USNRC licensing frameworks that have been developed for passive LWRs, LMRs and HTGRs can be adapted successfully to license FHRs. Upcoming work by a new committee of the ANS to create a safety standard for FHRs, ANS 20.1, will provide the basis to develop consensus-based FHR-specific GDC derived from existing LWR-specific GDC, to be used in licensing reviews.

Existing risk-informed approaches for identifying anticipated operational occurrences and design basis events can be readily adapted to identify these events for FHRs. To create a set of risk-informed event categories, the LBE selection process must develop a set of plausible initiating events based on a combination of informed judgment and a hierarchical system decomposition to develop failure modes for major reactor systems. Subsequently, the conceptual design phase PRA suggested for FHRs would categorize events based on the anticipated frequency using assigned, rather than observed, system reliability requirements. The assigned frequencies translate to functional requirements for the subsystem performance; functional requirements are instrumental in guiding future design development, and documenting the assumptions on which the current analysis is based.

The approach to identifying BDBEs and assessing the ability of an FHR to respond to and mitigate consequences of BDBEs requires further development, particularly because the high thermal margins of FHR fuel suggest that these reactors can be designed to have very robust and effective response to BDBEs even when they result in extensive plant damage. The possible elimination of offsite consequences appears to be unique to the combination of fuel and coolant in FHRs and merits consideration.

\title{
List of Acronyms
}

\author{
AHTR - Advanced High-Temperature Reactor \\ ANS - American Nuclear Society \\ AOO - anticipated operational occurrences \\ BDBE - beyond design basis event \\ CFR - U.S. Code of Federal Regulations \\ DOE - U.S. Department of Energy \\ DRACS - Direct Reactor Auxiliary Cooling System \\ EDMG -Extensive Damage Mitigation Guidelines \\ FHR - fluoride-salt-cooled, high-temperature reactor \\ GDC - USNRC General Design Criteria \\ H2TS - hierarchical two-tier scaling (analysis) \\ HTGR - high-temperature gas reactor \\ IRP - Integrated Research Project \\ LBE - licensing basis events \\ LMR - liquid metal reactor \\ LOFC - loss of forced circulation \\ LOHS - loss of heat sink \\ LS-VHTR - Liquid Salt Very High-Temperature Reactor \\ LWR - light-water reactor \\ MSR - molten salt reactor \\ MSRE - Molten Salt Reactor Experiment \\ NGNP - Next Generation Nuclear Plant \\ USNRC - U.S. Nuclear Regulatory Commission \\ ORNL - Oak Ridge National Laboratory
}


PASSC - Plant, Areas, Systems, Subsystems, and Components PB-AHTR - Pebble Bed Advanced High-Temperature Reactor PBMR - Pebble Bed Modular Reactor

PCU - power conversion unit

PRA - probabilistic risk assessment

PWR - pressurized-water reactor

SAMG - Severe Accident Management Guidelines

SDC - Safety Design Criteria

SFR - sodium-cooled fast reactor

SmAHTR - small modular Advanced High-Temperature Reactor S-PRISM - Super-Power Reactor Innovative Small Module

SS 316 - 316 stainless steel

SSCs - systems, structures, and components

TLRC - Top-Level Regulatory Criteria

TRISO - tristructural-isotropic 


\section{Acknowledgements}

This research was performed using funding received from the U.S. Department of Energy Office of Nuclear Energy's Nuclear Energy University Programs.

The authors sincerely appreciate the input of all of the experts who participated in the 2012 FHR workshops: Todd Allen (University of Wisconsin, Madison), Syd Ball (Oak Ridge National Laboratory), Thomas Downar (University of Michigan), George Flanagan (Oak Ridge National Laboratory), David Holcomb (Oak Ridge National Laboratory), Regis Matzie (ret. Westinghouse Electric Company), John McGaha (ret. Entergy), Dan Mears (Technology Insights), Matthew Memmot (Westinghouse Electric Company), James Rushton (ret. Oak Ridge National Laboratory), Robert Schleicher (General Atomics), Fred Silady (Technology Insights), Alexander Stanculescu (Idaho National Laboratory), Carl Stoots (Idaho National Laboratory), and Richard Wright (Westinghouse Electric Company); as well as the substantial

efforts of the graduate students and postdoctoral scholars who organized the workshops and compiled the FHR white papers.

\section{References}

[1] "Gas Turbine-Modular Helium Reactor (GT-MHR) Conceptual Design Description Report," General Atomics, San Diego, CA, 910720 Rev. 1, Jul. 1996.

[2] D. Matzer and E. Wallace, "PBMR moves forward with higher power and horizontal turbine," Mod. Power Syst., vol. 25, no. 1, pp. 11-15, 2005.

[3] C. Forsberg, P. F. Peterson, and P. S. Pickard, "Molten-Salt-Cooled Advanced High-Temperature Reactor for Production of Hydrogen and Electricity," Nucl. Technol., vol. 144, no. 3, pp. 289-302, 2003.

[4] D. T. Ingersoll, C. W. Forsberg, L. J. Ott, D. F. Williams, J. P. Renier, S. J. Ball, L. Reid, W. R. Corwin, and M. Vernon, "Status of Preconceptual Design of the Advanced High-Temperature Reactor (AHTR)," Oak Ridge National Laboratory, ORNL/TM-2004/104, May 2004.

[5] P. F. Peterson and H. Zhao, "A Flexible Base-Line Design for the Advanced High-Temperature Reactor Utilizing Metallic Reactor Internals (AHTR-MI)," in Proceedings of the 2006 International Congress on Advances in Nuclear Power Plants (ICAPP '06), 2006.

[6] T. Fei, D. Ogata, K. Pham, M. Solom, C. Zhao, C. Xu, A. Cheng, C. Eastridge, M. Foxe, B. Reinhart, J. Mintz, D. Caron, K. Evans, Z. Kline, D. Johnson, and A. Mai, "A Modular Pebble-Bed Advanced High Temperature Reactor," NE-170 Senior Design Project. Report No. UCBTH-08001. Department of Nuclear Engineering, University of California, Berkeley, 2008.

[7] A. T. Cisneros, M. R. Laufer, R. O. Scarlat, J. E. Seifried, and N. Zweibaum, "Fluoride-SaltCooled, High-Temperature Reactor (FHR) Subsystems Definition, Functional Requirements Definition, and Licensing Basis Events Identification White Paper," Department of Nuclear Engineering, University of California, Berkeley, UCBTH-12-001, 2013. Available from: fhr.nuc.berkeley.edu.

[8] A. T. Cisneros, N. Zweibaum, M. R. Laufer, R. O. Scarlat, and J. E. Seifried, "Fluoride-SaltCooled, High-Temperature Reactor (FHR) Methods and Experiments Program White Paper," Department of Nuclear Engineering, University of California, Berkeley, UCBTH-12-002, 2013. Available from: fhr.nuc.berkeley.edu.

[9] G. Cao, T. Gerczak, B. Kelleher, G. Zheng, D. Carpenter, A. T. Cisneros, L. Huddar, R. Romatoski, R. O. Scarlat, J. D. Stempien, and N. Zweibaum, "Fluoride-Salt-Cooled, HighTemperature Reactor (FHR) Materials, Fuels and Components White Paper," Department of 
Nuclear Engineering, University of California, Berkeley, UCBTH-12-003, 2013. Available from: fhr.nuc.berkeley.edu.

[10] D. Carpenter, J. Richard, R. Romatoski, J. D. Stempien, C. Andreades, G. Cao, A. T. Cisneros, L. Huddar, M. R. Laufer, D. Krumwiede, M. Munk, R. O. Scarlat, J. E. Seifried, G. Zheng, and N. Zweibaum, "Fluoride-Salt-Cooled, High-Temperature Reactor (FHR) Development Roadmap and Test Reactor Performance Requirements White Paper," Department of Nuclear Engineering, University of California, Berkeley, UCBTH-12-004, 2013. Available from: fhr.nuc.berkeley.edu.

[11] N. Zweibaum, G. Cao, A. T. Cisneros, B. Kelleher, M. R. Laufer, R. O. Scarlat, J. E. Seifried, M. H. Anderson, C. W. Forsberg, E. Greenspan, L.-W. Hu, P. F. Peterson, and K. Sridharan, "Phenomenology, methods and experimental program for fluoride-salt-cooled, high-temperature reactors (FHRs)," Prog. Nucl. Energy, this issue, 2014.

[12] J. Uhlir, "Chemistry and Technology of Molten Salt Reactors--History and Perspectives," J. Nucl. Mater., vol. 360, pp. 6-11, 2007.

[13] H. G. Macpherson, “The Molten Salt Reactor Adventure,” Nucl. Sci. Eng., vol. 90, pp. 374-380, 1985 .

[14] J. H. Shaffer, "Preparation and Handling of Salt Mixtures for the Molten Salt Reactor Experiment," Oak Ridge National Laboratory, ORNL-4616, 1971.

[15] M. Rosenthal, P. Haubenreich, and R. Briggs, "The Development Status of Molten-Salt Breeder Reactors," Oak Ridge National Laboratory, ORNL-4812, 1972.

[16] “NGNP Fuel Qualification White Paper,” Idaho National Laboratory, INL/EXT-10-18610, 2010.

[17] C. W. Forsberg, P. Pickard, and P. F. Peterson, "Molten-Salt-Cooled Advanced High- Temperature Reactor for Production of Hydrogen and Electricity," Nucl. Technol., vol. 144, pp. 289 - 302, 2003.

[18] D. T. Ingersoll, K. T. Clarno, C. W. Forsberg, J. C. Gehin, R. W. Christensen, C. B. Davis, G. L. Hawkes, J. W. Sterbentz, T. K. Kim, T. A. Taiwo, and W. S. Yang, "Status of Physics and Safety Analyses for the Liquid-Salt-Cooled Very High-Temperature Reactor (LS-VHTR)," Oak Ridge National Laboratory, ORNL/TM-2005/218, 2005.

[19] K. T. Clarno and J. C. Gehin, "Physics Analysis of the LS-VHTR: Salt Coolant and Fuel Block Design," in PHYSOR-2006, ANS Topical Meeting on Reactor Physics, 2006.

[20] W. A. Casino Jr., "Investigation of an Alternative Fuel Form for the Liquid Salt Cooled Very High Temperature Reactor (LS-VHTR)," in Proceedings of the 2006 International Congress on Advances in Nuclear Power Plants (ICAPP '06), 2006.

[21] C. Forsberg, L. Hu, P. F. Peterson, and T. Allen, "Fluoride-Salt-Cooled High-Temperature Reactors (FHRs) for Power and Process Heat," Massachusetts Institute of Technology, MIT-ANP$143,2012$.

[22] C. Forsberg, L. Hu, P. F. Peterson, and K. Sridharan, "Fluoride-Salt-Cooled High-Temperatire Reactors (FHRs) for Baseload and Peak Electricity, Grid Stabilization, and Process Heat," Massachusetts Institute of Technology, MIT-ANP-TR-147, 2013.

[23] P. Sabharwall, S. M. Bragg-Sitton, and C. Stoots, "Challenges in the development of high temperature reactors,” Energy Convers. Manag., vol. 74, pp. 574-581, Oct. 2013. 
[24] R. O. Scarlat and P. F. Peterson, "The current status of fluoride salt cooled high temperature reactor (FHR) technology and its overlap with HIF target chamber concepts," Nucl. Instruments Methods Phys. Res. Sect. A Accel. Spectrometers, Detect. Assoc. Equip., pp. 1-8, Jun. 2013.

[25] D. L. Krumwiede, R. O. Scarlat, J. K. Choi, T. M. Phan, and P. F. Peterson, "Three-Dimensional Modeling of the Pebble-Bed Fluoride-Salt-Cooled, High-Temperature Reactor (PB-FHR) Commercial Plant Design," in Proceedings of the American Nuclear Society 2013 Winter Meeting, 2013.

[26] S. R. Greene, J. C. Gehin, D. E. Holcomb, J. J. Carbajo, D. Ilas, A. T. Cisneros, V. K. Varma, D. F. Wilson, G. L. Y. Jr, F. J. Peretz, E. C. Bradley, G. L. Bell, and J. D. Hunn, "Pre-Conceptual Design of a Fluoride- Salt-Cooled Small Modular Advanced High-Temperature Reactor (SmAHTR)," Oak Ridge National Laboratory, ORNL/TM-2010/199, Dec. 2010.

[27] D. E. Holcomb, D. Ilas, V. K. Varma, A. T. Cisneros, R. P. Kelly, and J. C. Gehin, "Core and Refueling Design Studies for the Advanced High Temperature Reactor," Oak Ridge National Laboratory, ORNL/TM-2011/365, 2011.

[28] R. Hong, S. Huber, K. Lee, and P. Purcell, "Reactor Safety and Mechanical Design for the Annular Pebble-Bed Advanced High Temperature Reactor," NE-170 Senior Design Project, Department of Nuclear Engineering, University of California, Berkeley, UCBTH-09-001, 2009.

[29] D. L. Krumwiede, C. Andreades, A. T. Cisneros, L. Huddar, M. R. Laufer, R. O. Scarlat, J. Seifried, N. Zweibaum, E. Greenspan, and P. F. Peterson, "Design of a Pre-Conceptual Pebble-Bed, Fluoride-Salt-Cooled, High-Temperature Reactor Commercial Power Plant," Proceedings of ICAPP 2014. Charlotte, NC. April 6-9, 2014.

[30] "NGNP Licensing Basis Event Selection White Paper," Idaho National Laboratory, INL/EXT-1019521, Sep. 2010.

[31] D. Caron et. al., "A Modular Pebble-Bed Advanced High Temperature Reactor," NE-170 Senior Design Project, Department of Nuclear Engineering, University of California, Berkeley, UCBTH08-001, 2008.

[32] J. W. Collins, J. M. Beck, E. O. Opare, and L. F. Pincock, "NGNP - Creating Validated TRL and TDRMs for Critical Systems , Subsystems , and Components," Idaho National Laboratory, INL/EXT-08-14842, 2008.

[33] N. Zuber, G. E. Wilson, M. Ishii, W. Wulff, B. E. Boyack, A. E. Dukler, P. Griffith, J. M. Healzer, R. E. Henry, J. R. Lehner, F. J. Moody, M. Pilch, B. R. Sehgal, B. W. Spencer, T. G. Theofanous, and J. Valente, "An Integrated Structure and Scaling Methodology for Severe Accident Technical Issue Resolution: Development of Methodology," Nucl. Eng. Des., vol. 186, no. 1-2, pp. 1-21, 1998.

[34] N. Zuber, "The effects of complexity, of simplicity and of scaling in thermal-hydraulics," Nucl. Eng. Des., vol. 204, no. 1-3, pp. 1-27, 2001.

[35] N. Zuber, "An integrated structure and scaling methodology for severe accident technical issue resolution. Appendix D: A Hierarchical, two-tiered scaling analysis," U.S. Nuclear Regulatory Commission, NUREG/CR-5809, 1991.

[36] F. A. Silady, "Safety Classification Of Structures, Systems, and Components for the Pebble Bed Modular Reactor," Pebble Bed Modular Reactor, Document Number 04355 Rev. 1, 2006. 
[38] R. O. Scarlat, "Design of Complex Systems to Achieve Passive Safety : Natural Circulation Cooling of Liquid Salt Pebble Bed Reactors," Ph.D. Dissertation, Department of Nuclear Engineering, University of California, Berkeley, 2012.

[39] D. A. Petti, J. Buongiorno, J. T. Maki, R. R. Hobbins, and G. K. Miller, "Key differences in the fabrication, irradiation and high temperature accident testing of US and German TRISO-coated particle fuel, and their implications on fuel performance," Nucl. Eng. Des., vol. 222, pp. 281-297, 2003.

[40] T. Lambert, B. Grover, P. Guillermier, D. Moulinier, and F. I. Huart, "AGR-2: The first irradiation of French HTR fuel in Advanced Test Reactor," Nucl. Eng. Des., vol. 251, pp. 360-368, 2012.

[41] D. A. Petti, J. T. Maki, R. R. Hobbins, and G. K. Miller, "Key Differences in the Fabrication, Irradiation and Safety Testing of U.S. and German TRISO-coated Particle Fuel and Their Implications on Fuel Performance," Idaho National Engineering and Environmental Laboratory, INEEL/EXT-02-00300, 2002.

[42] J. Gomez, M. Hay, J. Lee, and B. Tam, "Design of Fuel Testing and Qualification Capsules for the Pebble Bed Advanced High Temperature Reactor," Department of Nuclear Engineering, University of California, Berkeley, UCBTH-10-002, 2010.

[43] S. R. Greene, J. C. Gehin, D. E. Holcomb, J. J. Carbajo, D. Ilas, A. T. Cisneros, V. K. Varma, D. F. Wilson, G. L. Yoder Jr, F. J. Peretz, E. C. Bradley, G. L. Bell, and J. D. Hunn, "Pre-Conceptual Design of a Fluoride-Salt-Cooled Small Modular Advanced High-Temperature Reactor (SmAHTR)," Oak Ridge National Laboratory, Oak Ridge, ORNL/TM-2010-199, 2010.

[44] C. W. Forsberg, P. F. Peterson, and L. Ott, "The Advanced High-Temperature Reactor (AHTR) for Producing Hydrogen to Manufacture Liquid Fuels," in Proceedings of the 2004 Americas Nuclear Energy Symposium, 2004.

[45] N. E. Woolstenhulme, D. M. Wachs, M. K. Meyer, H. W. Glunz, and R. B. Nielson, "Recent Accomplishments in the Irradiation Testing of Engineering- Scale Monolithic Fuel Specimens," in RERTR 2012 - International Meeting on Reduced Enrichment for Research and Test Reactors, 2012.

[46] "NGNP High Temperature Materials White Paper," Idaho National Laboratory, INL/EXT-0917187, 2010.

[47] J.-G. Nie, H.-S. Hu, J.-S. Fan, M.-X. Tao, S.-Y. Li, and F.-J. Liu, "Experimental study on seismic behavior of high-strength concrete filled double-steel-plate composite walls," J. Constr. Steel Res., vol. 88, pp. 206-219, Sep. 2013.

[48] A. H. Varma, S. R. Malushte, K. C. Sener, and Z. Lai, "Steel-plate composite (SC) walls for safety related nuclear facilities: Design for in-plane forces and out-of-plane moments," Nucl. Eng. Des., Oct. 2013.

[49] F. E. Haskin and A. L. Camp, "Perspectives on reactor safety," U.S. Nuclear Regulatory Commission, Mar. 1994. 
[50] D. F. Williams, L. M. Toth, and K. T. Clarno, “Assessment of Candidate Molten Salt Coolants for the Advanced High-Temperature Reactor (AHTR),” Oak Ridge National Laboratory, ORNL/TM2006/12, 2006.

[51] U.S. Nuclear Regulatory Commission, "Policy Statement on the Regulation of Advanced Reactors," vol. 73, no. 199, pp. 60612-60616, 2008.

[52] "Preapplication Safety Evaluation Report for the Power Reactor Innovative Small Module (PRISM) Liquid-Metal Reactor,” U.S. Nuclear Regulatory Commission, NUREG-1368, 1994.

[53] "Next Generation Nuclear Plant Structures, Systems, and Components Safety Classification White Paper," Idaho National Laboratory, INL/EXT-10-19509, 2010.

[54] "Next Generation Nuclear Plant Licensing Basis Event Selection White Paper,” Idaho National Laboratory, INL/EXT-10-19521, 2010.

[55] “Next Generation Nuclear Plant Probabilistic Risk Assessment White Paper,” Idaho National Laboratory, INL/EXT-11-21270, 2011.

[56] S. Kaplan and B. J. Garrick, "On The Quantitative Definition of Risk," Risk Anal., vol. 1, no. 1, pp. 11-27, Mar. 1981.

[57] "US Design Certification. Defense in Depth Approach for the Pebble Bed Modular Reactor," Pebble Bed Modular Reactor, 043593, 2006.

[58] F. Silady, "US Design Certification. Safety Classification Of Structures, Systems, and Components for the Pebble Bed Modular Reactor,” Pebble Bed Modular Reactor, Doc. 04355 Rev. 1, 2006.

[59] F. A. Silady, "Licensing Basis Event Selection for the Pebble Bed Modular Reactor," Pebble Bed Modular Reactor, Document Number 040251, 2006.

[60] "Regulatory Structure for New Plant Licensing, Part 1: Technology-Neutral Framework," U.S. Nuclear Regulatory Commission, NUREG-3-2005, 2005.

[61] “Proposal for a Technology-Neutral Safety Approach for New Reactor Designs,” International Atomic Energy Agency, IAEA-TECDOC-1570, 2007.

[62] E. D. Blandford, "Risk-informed Design Guidance for Advanced Reactor Concepts: A Case Study of the Pebble Bed Advanced High Temperature Reactor,” M.S. Report, Department of Nuclear Engineering, University of California, Berkeley, 2008.

[63] U.S. Nuclear Regulatory Commission, "Appendix A to 10 CFR 50 - General Design Criteria for Nuclear Power Plants," no. 24. 2007.

[64] "Nuclear Safety Design Process for Modular Helium-Cooled Reactor Plants," American Nuclear Society, ANSI/ANS-53.1-2011, 2011.

[65] H. Zhao and P. F. Peterson, "Optimization of Advanced High-Temperature Brayton Cycles with Multiple-Reheat Stages,” Nucl. Technol., vol. 158, no. 2, pp. 145-157, 2007. 
[66] "Standard Review Plan for the Review of Safety Analysis Reports for Nuclear Power Plants: LWR Edition," U.S. Nuclear Regulatory Commission, NUREG-0800 (formerly issued as NUREG75/087), 1987.

[67] "US Design Certification. Licensing Basis Event Selection for the Pebble Bed Modular Reactor," Pebble Bed Modular Reactor, 040251 Rev. 1, Jun. 2006.

[68] "TRISO-Coated Particle Fuel Phenomenon Identification and Ranking Tables (PIRTs) for Fission Product Transport Due to Manufacturing, Operations, and Accidents," U.S. Nuclear Regulatory Commission, NUREG/CR-6844, 2004.

[69] "Assessment of White Paper Submittals on Defense-in-Depth; Licensing-Basis Event Selection, and Safety Classification of Structures, Systems, and Components," U.S. Nuclear Regulatory Commission, ML13002A162, 2013.

[70] J. S. Armijo, "Next Generation Nuclear Plant (NGNP) Key Licensing Issues," U.S. Nuclear Regulatory Commission - Advisory Committee on Reactor Safeguards, ML13135A290, 2013.

[71] T. K. S. Liang, C. J. Chang, and H. J. Hung, "Development and assessment of the appendix K version of RELAP5-3D for LOCA licensing analysis," Nucl. Technol., vol. 139, no. 3, pp. 233$252,2002$.

[72] A. Bucalossi, A. Petruzzi, M. Kristof, and F. D'Auria, "Comparison Between Best-Estimate-PlusUncertainty Methods and Conservative Tools for Nuclear Power Plant Licensing," Nucl. Technol., vol. 172, pp. 29-47, 2010.

[73] C. Unal, B. Williams, F. Hemez, S. H. Atamturktur, and P. McClure, "Improved Best Estimate Plus Uncertainty Methodology, Including Advanced Validation Concepts, to License Evolving Nuclear Reactors," Nucl. Eng. Des., vol. 241, pp. 1813-1833, 2011.

[74] N. Zweibaum, G. Cao, A. T. Cisneros, B. Kelleher, M. R. Laufer, R. O. Scarlat, J. E. Seifried, M. H. Anderson, C. W. Forsberg, E. Greenspan, L.-W. Hu, P. F. Peterson, and K. Sridharan, "Phenomenology, methods and experimental program for fluoride-salt-cooled, high-temperature reactors (FHRs)," Prog. Nucl. Energy, this issue, 2014.

[75] C. Miller, A. Cubbage, D. Dorman, J. Grobe, G. Holahan, and N. Sanfilippo, "Recommendations for Enhancing Reactor Safety in the 21st Century.The Near-Term Task Force Review of Insights from the Fukushima Dai-Ichi Accident," U.S. Nuclear Regulatory Commission, ML111861807, 2011.

[76] R. Chang, J. Schaperow, T. Ghosh, J. Barr, C. Tinker, and M. Stutzke, "State-of-the-Art Reactor Consequence Analyses (SOARCA) Report," U.S. Nuclear Regulatory Commission, NUREG-1935, 2012.

[77] M. J. Mink, M. P. Short, and C. W. Forsberg, "Fluoride Salt-Cooled High-Temperature Reactor Severe Accident Strategy with Vessel Insulation Designed to Fail," in Proceedings of the 2013 International Congress on Advanced in Nuclear Power Plants (ICAPP '13), 2013.

[78] C. W. Forsberg, "Designing the Advanced High Temperature Reactor for Low Radionuclide Release in Beyond-Design-Basis-Accidents," in Proceedings of the 2008 International Congress on Advanced in Nuclear Power Plants (ICAPP '08), 2008. 
[79] V. K. Varma, D. E. Holcomb, F. J. Peretz, E. C. Bradley, D. Ilas, A. L. Qualls, and N. M. Zaharia, AHTR Mechanical, Structural, and Neutronic Preconceptual Design, ORNL/TM-2012/320, ORNL, Oak Ridge, TN, September 2012.

[80] “The Westinghouse Pressurized Water Reactor Nuclear Power Plant,” Westinghouse Electric Corporation, Water Reactor Divisions, 1984.

(http://www4.ncsu.edu/ doster/NE405/Manuals/PWR_Manual.pdf)

[81] "Technical Description of the PBMR Demonstration Power Plant," Document Number 016956, Rev. 4, 2006.

[82] E. A. Hoffman, W.S. Yang, and R.N. Hill, "Preliminary Core Design Studies for the Advanced Burner Reactor over a Wide Range of Conversion Ratio," Argonne National Laboratory, ANLAFCI-177, Tables 4.1, 4.3, and 4.4, 2006. 


\section{Tables}

Table 1. Comparison of design parameters for PB-FHR, AHTR, and other advanced reactors [79][82]

\begin{tabular}{|c|c|c|c|c|c|}
\hline & $\begin{array}{l}\text { Mk1 } \\
\text { PB- } \\
\text { FHR }\end{array}$ & $\begin{array}{c}\text { ORNL } \\
2012 \\
\text { AHTR }\end{array}$ & $\begin{array}{c}\text { Westing- } \\
\text { house } \\
\text { 4-loop } \\
\text { PWR }\end{array}$ & PBMR & $\begin{array}{c}\text { S- } \\
\text { PRISM }\end{array}$ \\
\hline Reactor thermal power (MWt) & 236 & 3400 & 3411 & 400 & 1000 \\
\hline Reactor electrical power (MWe) & 100 & 1530 & 1092 & 175 & 380 \\
\hline Fuel enrichment $\dagger$ & $19.90 \%$ & $9.00 \%$ & $4.50 \%$ & $9.60 \%$ & $8.93 \%$ \\
\hline Fuel discharge burn up (MWt-d/kg) & 180 & 71 & 48 & 92 & 106 \\
\hline Fuel full-power residence time in core (yr) & 1.38 & 1.00 & 3.15 & 2.50 & 7.59 \\
\hline Power conversion efficiency & $42.4 \%$ & $45.0 \%$ & $32.0 \%$ & $43.8 \%$ & $38.0 \%$ \\
\hline Core power density $\left(\mathrm{MW} / \mathrm{m}^{3}\right)$ & 22.7 & 12.9 & 105.2 & 4.8 & 321.1 \\
\hline Fuel average surface heat flux (MW/m²) & 0.189 & 0.285 & 0.637 & 0.080 & 1.13 \\
\hline Fuel specific surface area (area/volume) $(1 / \mathrm{m})$ & 120 & 45 & 165 & 60 & 285 \\
\hline Reactor vessel diameter $(\mathrm{m})$ & 3.5 & 10.5 & 6.0 & 6.2 & 9.0 \\
\hline Reactor vessel height (m) & 12.0 & 19.1 & 13.6 & 24.0 & 20.0 \\
\hline Reactor vessel specific power (MWe/m³) & 0.866 & 0.925 & 2.839 & 0.242 & 0.299 \\
\hline Start-up fissile inventory (kg-U235/MWe) $\dagger \dagger$ & 0.79 & 0.62 & 2.02 & 1.30 & 6.15 \\
\hline EOC Cs-137 inventory in core $(\mathrm{g} / \mathrm{MWe}) *$ & 30.8 & 26.1 & 104.8 & 53.8 & 269.5 \\
\hline EOC Cs-137 inventory in core $(\mathrm{Ci} / \mathrm{MWe}){ }^{*}$ & 2672 & 2260 & 9083 & 4667 & 23359 \\
\hline Spent fuel dry storage density $\left(\mathrm{MWe}-\mathrm{d} / \mathrm{m}^{3}\right)$ & 4855 & 2120 & 15413 & 1922 & - \\
\hline Natural uranium (MWe-d/kg-NU) ** & 1.56 & 1.47 & 1.46 & 1.73 & - \\
\hline Separative work (MWe-d/kg-SWU) ** & 1.98 & 2.08 & 2.43 & 2.42 & - \\
\hline
\end{tabular}

$\dagger$ For S-PRISM, effective enrichment is the Beginning of Cycle weight fraction of fissile $\mathrm{Pu}$ in fuel

$\dagger$ Assume start-up U-235 enrichment is $60 \%$ of equilibrium enrichment; for S-PRISM startup uses fissile $\mathrm{Pu}$

* End of Cycle (EOC) life value (fixed fuel) or equilibrium value (pebble fuel)

** Assumes a uranium tails assay of 0.003 . 
Table 2. HTGR Licensing Strategy (adapted from [58])

\begin{tabular}{|c|c|c|}
\hline & Metric & Purpose \\
\hline 1 & Top-Level Regulatory Criteria (TLRC) & Establish what must be achieved \\
\hline 2 & $\begin{array}{l}\text { LBE } \\
\text { Deterministic DBAs }\end{array}$ & Define when the TLRC must be met \\
\hline 3 & $\begin{array}{l}\text { SDC } \\
\text { Safety Classifications of SSCs } \\
\text { Defense-in-Depth }\end{array}$ & $\begin{array}{l}\text { Establish how it will be assured that } \\
\text { the TLRC are met }\end{array}$ \\
\hline 4 & Special Treatment Requirements & $\begin{array}{l}\text { Provide assurance as to how well the } \\
\text { TLRC are met }\end{array}$ \\
\hline
\end{tabular}

Table 3. FHR Safety Design Criteria and equivalent top level criteria lists for PBMR and LMR [7], [58]

\begin{tabular}{|l|l|l|}
\hline \multicolumn{1}{|c|}{$\begin{array}{c}\text { FHR } \\
\text { Safety Design Criteria }\end{array}$} & \multicolumn{1}{c|}{\begin{tabular}{c}
\multicolumn{1}{c|}{ PBMR } \\
Safety Functions
\end{tabular}} & \multicolumn{1}{c|}{$\begin{array}{c}\text { LMR } \\
\text { Top-Level Safety Functions }\end{array}$} \\
\hline $\begin{array}{l}\text { 1. Maintain control of } \\
\text { radionuclides }\end{array}$ & 1. Maintain Control of & 1. Overall Protection \\
2. Control heat generation & Radionuclides & 2. Core Heat Removal \\
(reactivity) & 2. Control Heat Generation & 3. Reactivity Control \\
3. Control heat removal and & (Reactivity) & 4. Maintenance of Coolant \\
addition & 3. Control Heat Removal & Inventory \\
4. Control primary coolant & 4. Control Chemical Attack & 5. Residual Heat Removal \\
inventory & 5. Maintain Core and Reactor & 6. Containment of Radioactive \\
5. Maintain core and reactor & Vessel Geometry & Material \\
vessel geometry & 6. Maintain Reactor Building & 7. Containment Heat Removal \\
6. Maintain reactor building & Structural Integrity & 8. Prevention and Mitigation of \\
structural integrity & & Energetic Reactions \\
\hline
\end{tabular}


Table 4. Preliminary List of FHR Initiating Events Based on Postulated Failure Modes of Susbsystems

\begin{tabular}{|c|}
\hline $\begin{array}{l}\text { (1) Increase in heat removal from the primary coolant } \\
\text { Inadvertent opening of one or all DRACS loop air dampers } \\
\text { Inadvertent increase in shut-down cooling system flow rate } \\
\text { Inadvertent increase in one or all intermediate loop flow rates } \\
\text { Reactor-turbine load mismatch } \\
\text { Loss of electrical heating system } \\
\text { Inadvertent primary pump start }\end{array}$ \\
\hline $\begin{array}{l}\text { (2) Decrease in heat removal from the primary coolant } \\
\text { Inadvertent loss of heat removal via shut-down cooling system or DRACS } \\
\text { Loss of intermediate loop heat removal } \\
\text { Loss of power conversion unit } \\
\text { Inadvertent increase in electric heating system } \\
\text { Major or Minor break in the DRACS or intermediate loop } \\
\text { Trip of one or more primary or coolant pumps } \\
\text { Pressurization of intermediate loop from air ingress due to PCU heat exchanger failure }\end{array}$ \\
\hline $\begin{array}{c}\text { (3) Decrease in reactor coolant system flow rate } \\
\text { Loss of offsite power } \\
\text { Trip of any or all primary pumps } \\
\text { Single reactor coolant pump locked rotor } \\
\text { Increase in bypass flow } \\
\end{array}$ \\
\hline $\begin{array}{c}\text { (4) Reactivity and power distribution anomalies } \\
\text { Inadvertent injection of soluble poisons } \\
\text { Inadvertent loss of primary coolant chemistry control } \\
\text { Single failure of a control element } \\
\text { Operation with a fuel assembly in improper position (fixed fuel) } \\
\text { Inadvertent loss of confidence in pebble bed geometry } \\
\text { Inadvertent removal of one or all control rods }\end{array}$ \\
\hline $\begin{array}{l}\text { (5) Increase in reactor coolant inventory } \\
\text { Inadvertent injection of secondary, DRACS, or buffer salt into the reactor vessel }\end{array}$ \\
\hline $\begin{array}{c}\text { (6) Decrease in reactor coolant inventory } \\
\text { Intermediate heat exchanger leak } \\
\text { Minor primary leak or loss of reactor coolant from a small rupture (for loop design) } \\
\text { Major rupture of a pipe containing primary coolant (for loop design) } \\
\text { Inadvertent removal of coolant by volume control system (potentially initiated by ingestion of cover gas } \\
\text { into primary coolant causing level rise) } \\
\text { Minor rupture of reactor vessel } \\
\text { Major rupture of reactor vessel } \\
\text { Rupture of guard vessel }\end{array}$ \\
\hline $\begin{array}{l}\text { (7) Radioactive release from a subsystem or component } \\
\text { Inadvertent release or failure of tritium control system } \\
\text { Inadvertent generation and mobilization of primary coolant particulates (also presents Berylium } \\
\text { exposure hazard) }\end{array}$ \\
\hline
\end{tabular}


Figures

\begin{tabular}{|c|c|c|c|c|c|}
\hline \multicolumn{3}{|c|}{ PASSC NGNP Convention } & & \multirow[b]{2}{*}{$\begin{array}{l}\text { Functional } \\
\text { Requirements }\end{array}$} & \multirow[b]{2}{*}{$\begin{array}{l}\text { SSCs } \\
\text { Classificatior }\end{array}$} \\
\hline \multirow[t]{3}{*}{ AREAS } & SYSTEMS & SUBSYSTEMS COMPONENTS & & & \\
\hline & "Systems, & $\begin{array}{l}\text {, Structures, and Components" } \\
\text { (SSCs) }\end{array}$ & & & \\
\hline & & SUBSYSTEMS MODULES & CONSTITUENTS $\begin{array}{l}\text { GEOMETRICAL } \\
\text { CONFIGURATIONS }\end{array}$ PHASES FIELDS & \multirow[t]{2}{*}{$\begin{array}{l}\text { Phenomena } \\
\text { Identification }\end{array}$} & \multirow[t]{2}{*}{$\begin{array}{l}\text { Modeling, } \\
\text { SETs, IETs }\end{array}$} \\
\hline & & H2TS Decomposition Para & & & \\
\hline
\end{tabular}

Figure 1. FHR System Decomposition Paradigm

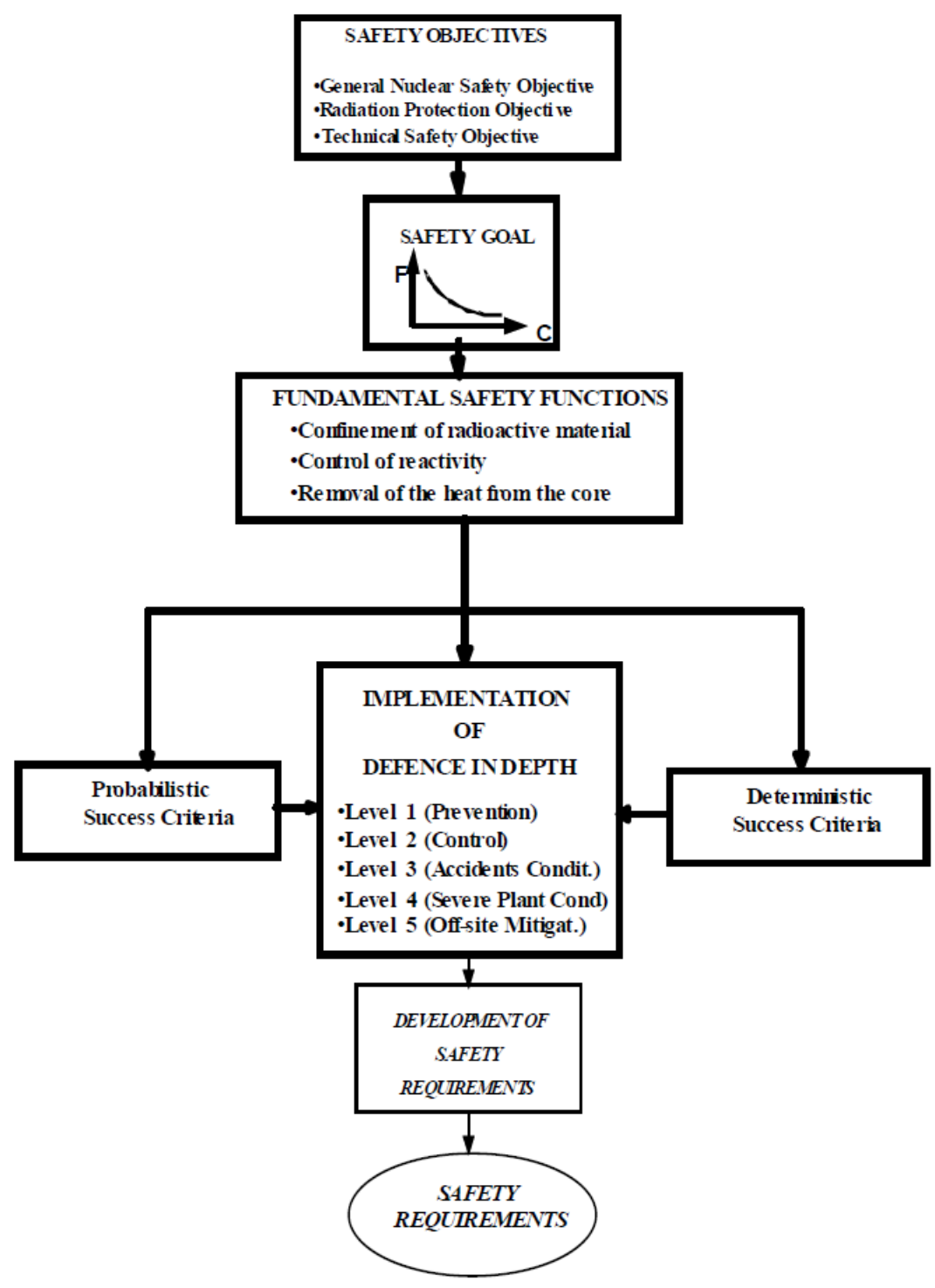

Figure 2. Technology-neutral framework proposed by IAEA [61] 


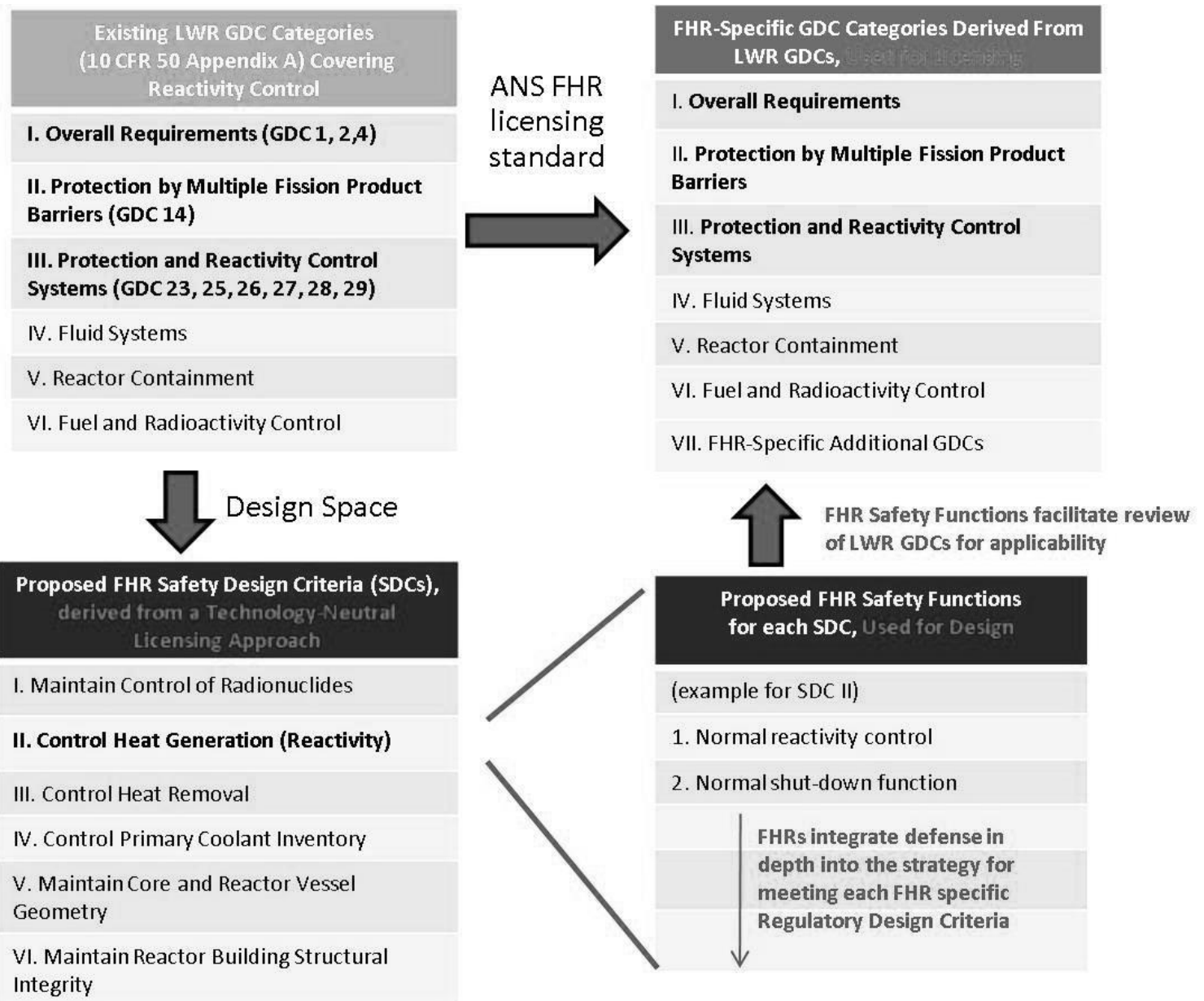

\section{Figure 3. FHR-Specific SDC Categories and FHR Detailed Safety Functions}

\begin{tabular}{|c|c|c|c|c|c|}
\hline $\begin{array}{l}\text { Initiating } \\
\text { Event }\end{array}$ & $\begin{array}{l}\text { Response to } \\
\text { Initiating Event }\end{array}$ & & & & \\
\hline $\begin{array}{c}\text { Loss of Power } \\
\text { Conversion } \\
\text { Unit }\end{array}$ & $\begin{array}{c}\text { Reactor Trip via } \\
\text { Reactivity Control } \\
\text { System }\end{array}$ & \begin{tabular}{|c|} 
Core Heat Removal \\
via Normal \\
Shutdown Cooling \\
System \\
\end{tabular} & $\begin{array}{c}\text { Core Heat Removal } \\
\text { via DRACS Natural } \\
\text { Circulation }\end{array}$ & $\begin{array}{c}\text { Sequence } \\
\text { Frequency } \\
(1 / \mathrm{R}-\mathrm{yr})\end{array}$ & $\begin{array}{l}\text { Sequence } \\
\text { Category }\end{array}$ \\
\hline 5 & 1 & 1 & & 5 & $\mathrm{AOO}$ \\
\hline \multicolumn{6}{|l|}{ (1/R-yr) } \\
\hline & & & $1 \times 10^{-5}$ & $<5 \times 10^{-7}$ & --- \\
\hline & $1 \times 10^{-6}$ & & 1 & $5 \times 10^{-6}$ & BDBE \\
\hline & & & $1 \times 10^{-5}$ & $<5 \times 10^{-7}$ & --- \\
\hline
\end{tabular}

Figure 4. Sample FHR Event Tree for Loss of the PCU 